\title{
A EMERGÊNCIA DO EDUCADOR AMBIENTAL CRÍTICO A PARTIR DA FORMAÇÃO DOCENTE: IMPORTÂNCIA DO SABER SOCIOAMBIENTAL NA CONSTRUÇÃO DE PROJETOS DE INTERVENÇÃO COLETIVOS
}

Luanne Michella Bispo Nascimento ${ }^{1}$ Aline Lima de Oliveira Nepomuceno²

Celso Daniel Mandlate ${ }^{3}$ Denio Alberto Barbosa Tavares ${ }^{4}$

Resumo: A formação docente em educação ambiental pode auxiliar no enfrentamento de uma lógica hegemônica que não promove reflexões dos padrões societários almejados. Nesse intento, o presente artigo nos propicia a reflexão sobre a necessidade de repensar e de reconstruir os programas de formação docente em educação ambiental. A partir das interpretações do trabalho de campo realizado no povoado Caueira, Itaporanga-Se, discutimos como a formação do educador ambiental crítico pode contribuir para a elaboração de projetos de intervenção coletivos nas unidades escolares. A metodologia adotada no campo foi a Abordagem HermenêuticaFenomenológica Complexa, que subsidiou a propositura de uma formação docente contra hegemônica.

Palavras-chave: Abordagem Hermenêutica-Fenomenológica Complexa; Formação Docente; Educador Ambiental Crítico; Participação; Saber Ambiental.

1 Universidade Federal de Sergipe. E-mail: Iuanne_12@hotmail.com.

2 Universidade Federal de Sergipe. E-mail: aline_limadeoliveira@yahoo.com.br.

3 Universidade Federal de Sergipe. E-mail: celsodanielmandlate@gmail.com.

4 Universidade Federal de Sergipe. E-mail: dabt234@yahoo.com.br. 
Abstract: Teacher education in environmental education can assist in coping with a hegemonic logic that does not promote reflections on the desired corporate standards. To this end, this article provides us with a reflection on the need to rethink and reconstruct teacher training programs in environmental education. Based on the interpretations of the fieldwork carried out in the Caueira village, Itaporanga-Se, we discussed how the formation of the critical environmental educator can contribute to the development of collective intervention projects in the school units. The methodology adopted in the field was the Complex Hermeneutic-Phenomenological Approach, which supported the proposition of a teacher training against hegemony.

Keywords: Complex Hermeneutic-Phenomenological Approach; Teacher Education; Critical Environmental Educator; Participation; Environmental Knowledge.

\section{Introdução}

Frente à crise societária que atravessamos atualmente, o papel social da escola precisa ser redimensionado a fim de se promover uma educação preocupada com a formação de cidadãos mais conscientes com os problemas socioambientais e capazes de pensarem/refletirem sobre suas possíveis soluções, uma vez que muitas das vezes são causados por seus modos e estilos de vida.

Entretanto, não se trata apenas da transferência de conhecimentos, mas de como proporcionar a participação dos cidadãos nas discussões e decisões sobre a questão ambiental. Uma proposta para subverter a lógica dominante do conhecimento científico preponderante na educação básica que invisibiliza os conhecimentos e valores do educando, é trabalhar com a Educação Ambiental (EA) na perspectiva crítica.

Apenas na perspectiva que parte do pressuposto de que a sociedade é o espaço inerente do conflito social, é possível perceber a correlação de forças no próprio campo da Educação Ambiental, e assim, ver como foi cooptada e instrumentalizada, deixando de ser subversiva e se convertendo numa extraordinária peça publicitária da sociabilidade do capital (LAYRARGUES, 2018, p. 41).

Assim, segundo o mesmo autor, para trabalhar a EA na perspectiva crítica, faz-se necessário assumir o radicalismo no projeto revolucionário a ser instituído. É preciso também criar, nas unidades escolares, um ambiente capaz de promover o envolvimento dos docentes com os discentes, no somatório de forças e capacidades específicas. 
Todavia, o engessamento curricular muitas vezes impede o professor de trabalhar nessa perspectiva. Do ponto de vista prático, o currículo é abstrato, pois as concretizações são efetivadas pelas práticas docentes que precisam ser intencionalizadas, reflexivas e subversivas. Nesse intento, é possível transpor as barreiras institucionais, evitando discursos alienadores que homogeneíze suas ações. Considerando essa assertiva, a formação docente precisa auxiliar nessa transposição, fomentando a inserção das particularidades regionais nos conteúdos curriculares e subsidiando uma prática cotidiana integrativa e interdisciplinar.

Essa formação precisa proporcionar a possibilidade de ruptura com a lógica de obediência dominante no intuito de transformar e transpor essa realidade, fundada numa lógica contra hegemônica, proporcionando a interação com realidades factíveis que extrapolem aquelas estipuladas (SILVA; ARAÚJJO, 2019). Em busca de caminhos alternativos, pautados em uma nova filosofia de mundo, o professor educador ambiental necessita desenvolver as habilidades humanas de pensar, sentir, fazer, resistir e de enfrentar. Por conseguinte, poderão auxiliar na formação de educandos éticos, autônomos, reflexivos, críticos e transformadores de um meio ambiente ecologicamente sustentável.

Dessa forma, partimos da prerrogativa de que a formação docente em EA pode colaborar para o desenvolvimento de uma consciência reflexiva e transcendente do educador ambiental, pois sua reflexão estaria inserida numa projeção para o futuro, de acordo com seus anseios. Nessa lógica, as práticas pedagógicas docentes precisam instigar a construção do conhecimento integrativo, considerando não somente os conteúdos curriculares propostos, mas os conhecimentos de seus educandos. Diante disso, a escola poderia funcionar como mediadora de vivências diversificadas dos sujeitos protagônicos de saberes e fazeres locais na construção de projetos de intervenção coletivos (JACOBI; TRISTÃO; FRANCO, 2009).

Assim, o presente artigo tem como objetivo discutir a importância da formação docente em Educação Ambiental na construção do conhecimento integral e significativo, promovendo, assim, um processo educacional mais interativo. Para tanto, discutiremos a partir das percepções do trabalho de campo realizado, proposto na disciplina Formação de Professores e Educação Ambiental, ministrada no âmbito do Programa de Pós-Graduação em Educação (PPGED), da Universidade Federal de Sergipe (UFS). A discussão pormenorizará como a formação de educadores ambientais críticos pode contribuir para a desfragmentação do saber disciplinar e popular nas redes básicas de ensino. Consequentemente, as modificações comportamentais advindas dessa formação poderiam contribuir para o entendimento da necessidade de engajamento e participação discente, suscitando desenvolvimento de projetos de intervenção em coletivo. 


\section{A formação docente para a emergência do educador ambiental}

No âmbito educacional, a EA deverá ser trabalhada em todas as instâncias de formação e disciplinas dos currículos, integrando-se ao processo educacional mais do que um tema transversal. Portanto, é preciso apreendê-la como preparação de pessoas para as suas vidas enquanto membros de uma sociedade coletiva. Seu aprendizado possibilita a aquisição de conhecimentos, valores e atitudes necessárias para proteger e melhorar o meio ambiente em que vivem, além de fornecer subsídios para mudanças socioculturais que empoderem os indivíduos em condições de vulnerabilidade. Assim, a EA:

[...]teria como finalidade promover a compreensão da existência e da importância da interdependência econômica, política, social e ecológica da sociedade; proporcionar a todas as pessoas a possibilidade de adquirir conhecimentos, 0 sentido dos valores, o interesse ativo e as atitudes necessárias para proteger e melhorar a qualidade ambiental; induzir novas formas de conduta nos indivíduos, nos grupos sociais e na sociedade em seu conjunto, tornando-a apta a agir em busca de alternativas de soluções para seus problemas ambientais, como forma de elevação da sua qualidade de vida (DIAS, 2004, p.83).

$\mathrm{Na}$ contramão dessa asseveração, as práticas corriqueiras pautadas em ações de EA, muitas vezes são ingênuas e promovem uma acriticidade da problemática ambiental, além de não suscitarem seu enfrentamento e/ou superação. Para evitar os reducionismos existentes nas práticas de EA, é necessário que os programas de formação docente sejam repensados:

Os programas de formação de professores precisam se constituir mais críticos e socialmente comprometidos a fim de formar profissionais capazes de identificar os interesses da classe dominante contidos nas políticas educacionais, de modo a contribuir na construção de uma escola comprometida com a democracia e a justiça social, e ainda que saibam articular cultura científica e cultura popular, gerando movimentos contrahegemônicos que sejam capazes de produzir mudanças na realidade socioambiental contemporânea (SILVA; ARAÚJO, 2019, p.85).

Nessa lógica, a formação em EA precisa fomentar debates que busquem integrá-la a informações e reflexões críticas socioambientais, suscitando a emergência do educador ambiental. Isso quer dizer que se formariam docentes aptos a resistirem às imposições inculcadas pela hegemonia reprodutivista dos programas, e assim, à permitirem seus alunos perceberem-se inseridos no

Revista brasileira educação ambiental 
meio ambiente, auxiliando na superação da visão dicotomizada entre o ser humano e a natureza. Com isso, a educação estaria voltada para a formação de pessoas críticas e capazes de interpretar o seu contexto social, cultural e ambiental, além de apontar caminhos alternativos de ações para a superação de problemáticas inseridas no cotidiano de cada aluno.

A EA constituiria assim, uma ferramenta de valorização do trabalho de experimentação, de reflexão e de planejamento nas escolas. Tornar-se-ia papel destas, o asseguramento de condições aos alunos para que desenvolvam competências e habilidades contextualizadoras dos conceitos apreendidos para a vivência do seu universo sociocultural. Tais aquisições podem subsidiar uma melhor compreensão e enfrentamento das injustiças socioambientais, provenientes das disparidades socioeconômicas inerentes à nossa sociedade.

As práticas educativas ambientalmente sustentáveis nos apontam para propostas pedagógicas centradas na criticidade e na emancipação dos sujeitos, com vistas à mudança de comportamento e atitudes, ao desenvolvimento da organização social e da participação coletiva. Nessa proposta de educação reflexiva e engajada, centrada nos saberes e fazeres construídos com e não para os sujeitos aprendentes e ensinantes, a Educação Ambiental difere substancialmente da informação ambiental. Esta ainda é focada na elaboração e transmissão de conteúdos descontextualizados e "despolitizados", no sentido de instaurar mudanças efetivas na realidade através da tessitura de um conhecimento crítico, intencionalmente engajado (JACOBI; TRISTÃO; FRANCO, 2009, p.67).

Dessa forma, poderia conferir à formação em EA uma emersão do seu conservadorismo pedagógico e da subserviência à lógica do capital. Assim, seu conteúdo crítico ecopolítico, historicamente esvaziado ao decorrer do tempo, seria recuperado, oportunizando o resgate de seu poder subversivo e de seu potencial contestatório, necessários para a construção de sociedades sustentáveis (LAYRARGUES, 2018).

A formação docente precisa assim, possibilitar a construção de um conhecimento mais abrangente, proporcionando aos professores uma compreensão crítica global do ambiente. Com isso, apresentaria uma funcionalidade não pragmática de subsidiar o radicalismo necessário no projeto societário revolucionário orientado pela transformação social, principalmente daqueles comumente subalternizados (LAYRARGUES, 2018). 


\section{Conhecimento integrativo: o saber ambiental}

Os problemas ambientais atingem a todos, independentemente da profissão e classe social. Educar ambientalmente é possibilitar processos educativos e práticas pedagógicas que fomentem uma reorganização da sociedade, a fim de que reflitam sobre os principais problemas socioambientais, pensando em metas para solucioná-lo ou ao menos mitigá-los (RODRIGUES; SILVA, 2010). Para tanto, a comunidade escolar deve ser dotada de conhecimentos e atitudes necessárias para uma melhor tomada de decisão em prol do respeito ao meio ambiente:

Dessa forma, o pensamento, a capacidade de reflexividade, de conhecer o mundo, de tomar decisões, fazer escolhas e transformar veem-se ampliados pela intencionalidade dos processos educativos. Estes colocam em pauta práticas educativas capazes de integrar relações e ações sociais de caráter colaborativo em contextos significativos, que aliam saberes e práticas sociais cotidianas de intervenção na realidade local (JACOBI; TRISTÃO; FRANCO, 2009, p.70).

Partindo dessa concepção e para que haja um trabalho mais eficaz, é indispensável o envolvimento de todos. A instituição escolar precisa estar preparada para incorporar a temática ambiental em seu currículo, integrando o conhecimento disciplinar e o popular, pois é o lugar mais adequado para trabalhar a relação ser humano-ambiente-sociedade, e formar um ser humano novo, crítico e criativo (MELLER, 1997).

Sendo assim, o educador ambiental pode colaborar com 0 desenvolvimento de uma compreensão integrada do Meio Ambiente, em suas múltiplas e complexas relações, envolvendo todos os aspectos da vida humana. Ao propiciar a apreensão da complexidade ambiental, poderia também presenciar a construção de uma consciência comunitária, por meio da modificação do comportamento e os hábitos dos envolvidos no processo educacional (SANTOS et al., 2013).

Nesse intento, segundo Leff (2011) a EA se fundamentaria em dois princípios básicos: uma nova ética que orienta os valores e comportamentos para os objetivos de sustentabilidade ecológica e a equidade social; uma nova concepção do mundo como sistemas complexos, a reconstituição do conhecimento e o diálogo de saberes:

Partindo dessa concepção, a Educação Ambiental elimina fronteiras entre escola e comunidade, ao tomar como eixo do trabalho pedagógico a problemática socioambiental. Considera como espaços/tempos educativos o que acontece dentro e fora da escola, como lócus privilegiado, integrado e essencial para a criação de processos colaborativos de resolução de problemas locais, num movimento essencial em sintonia com 
temas da contemporaneidade, associados com a crise ambiental em escala planetária (JACOBI; TRISTÃO; FRANCO, 2009, p.70).

A transposição fronteiriça exprimiria a construção de um saber socioambiental que se definiria em relação a cada uma das disciplinas já constituídas, através de um processo social de produção do conhecimento:

O saber ambiental problematiza o conhecimento fragmentado em disciplinas e a administração setorial do desenvolvimento, para constituir um campo de conhecimentos teóricos e práticos orientado para a rearticulação das relações sociedadenatureza. Este conhecimento não se esgota na extensão dos paradigmas da ecologia para compreender a dinâmica dos processos socioambientais, nem se limita a um componente ecológico nos paradigmas atuais do conhecimento (LEFF, 2011, p. 145).

Essa elucubração nos convida ao entendimento de não utilizar o conhecimento disciplinar como ferramenta normativa e legitimadora, promovendo exclusões de outras formas de conhecimento. Nessa contramão, o educador ambiental precisa favorecer diálogos conscientes entre as diferenças, permitindo 0 reconhecimento dos saberes e contextos socioculturais em jogo. Assim, as aproximações entre as formas de conhecimento podem proporcionar aos educandos uma maior compreensão sobre a complexidade ambiental da perspectiva do conhecimento curricular, evitando a desvalorização do seu conhecimento culturalmente construído.

O chamado saber local das comunidades e seus fundamentos não são, necessariamente, os mesmos do saber técnico e acadêmico e, por isso, tornase elemento constituinte de um saber maior, mais abrangente e complexo (LEFF, 2011). De acordo com o mesmo autor:

O saber ambiental sendo um processo em construção complexo contrariaria os "paradigmas normais" do conhecimento. Ele ultrapassa o campo da racionalidade científica e da objetividade do conhecimento, propondo a revalorização de um conjunto de saberes sem pretensão de cientificidade (LEFF, 2006, p. 168).

Haveria, assim, uma busca por outros saberes desconhecidos, ignorados e subjugados pela ciência da modernidade. O conhecimento disciplinar apresenta caráter limitado e parcial, pois não estabelece conexões entre o social e o natural. Visando sua maior abrangência, faz-se necessário a internalização do saber ambiental e uma superação paradigmática, requerendo a adoção do pensamento complexo e de metodologias alternativas. 
Pensando em possibilidades de proposituras subversivas de uma formação docente em EA, que auxiliem no desvelamento das idiossincrasias silenciadas, e na busca do projeto societário necessário para a realidade local, seguiremos com a descrição do trabalho de campo realizado, e a proposta de formação docente subsequente:

Daí a necessidade de se reafirmar o compromisso ético-político com as sociedades sustentáveis, e de firmar outro compromisso político-pedagógico no campo da Educação Ambiental, com a ampla sinalização de pertencimento a outro campo para além do capital, assumindo a radicalidade da luta anticapitalista, a partir da perspectiva do oprimido como condição de superação da cooptação reprodutivista (LAYRARGUES, 2018, p. 41).

A imersão no conjunto de atividades discursivas e práticas vivenciadas auxiliou na percepção do que é ocultado e na cognição sobre a complexidade e a politização inerentes à formação ambiental. Além disso, possibilitou a evidenciação da indispensabilidade da participação coletiva e do engajamento dos sujeitos envolvidos no processo educativo.

\section{Imergindo no campo de trabalho: passos para a superação da hegemonia estabelecida}

Para trabalhar a formação docente em EA, foi proposta a realização de uma imersão em um final de semana no povoado Caueira, município de Itaporanga D'Ajuda, Sergipe. Além de realizarmos discussões teóricas referentes às temáticas anteriormente relatadas, realizamos um trabalho de campo no referido povoado.

Dos locais propostos, escolhemos a Escola Municipal José Sobral Garcez Filho como lócus de pesquisa. Na unidade escolar funcionam todas as séries iniciais do ensino fundamental. Apesar de só possuir três salas de aula, apresenta uma boa infraestrutura, pois possui pátio coberto, equipamentos tecnológicos (TV, DVD, datashow e som), acesso à internet, além de ofertar alimentação aos alunos.

Para evitar abordar problemáticas incoerentes, que trariam percepções imparciais da realidade, não escolhemos nenhumas das problemáticas propostas pelas professoras da disciplina. Ao invés disso, propusemo-nos a identificar as reais problemáticas a partir dos discursos dos atores sociais em nosso "bate-papo".

Três funcionárias da unidade escolar participaram da nossa conversa. Duas delas são professoras dos $3^{\circ}$ e $4^{\circ}$ anos no período vespertino, e a terceira é secretária, a responsável pela escola na ocasião. Descontraidamente, desconstruímos a ideia de estrangeiros invasores, 
minimizando as possíveis resistências dos entrevistados e evitando dados maquiados e respostas espelhos.

Dessa forma, estabelecemos alguns temas para nortear a conversa, e a partir dela, listamos quais seriam as principais problemáticas colocadas pelos respondentes. Tal posicionamento se deu para evitar que sugeríssemos uma formação pautada em uma problemática não concernida à realidade do povoado. As questões foram pensadas de forma a não conduzir e não influenciar as respostas: 1. Como a escola tem abordado os problemas socioambientais do povoado? 2. Como é viver aqui? 3. Qual sua opinião sobre a problemática socioambiental da localidade? Há alguma relação com os costumes e práticas culturais locais? 4. A escola tem contribuído para a qualidade de vida, convivência e manutenção de recursos naturais?

Nesse ínterim, adotamos a postura metodológica da perspectiva da Abordagem Hermenêutica-Fenomenológica Complexa (AHFC), caracterizada pela indissociabilidade nos processos de descrição e interpretação da experiência humana (FREIRE, 2012). Procedemos com a análise a partir da textualização literal das experiências apreendidas, seguida da tematização, operacionalizada pela busca dos elementos textuais que colaborariam para a cognição dos fenômenos, devido ao sentido que contêm ou expressam (D'ESPOSITO; COSTA NEVES, 2015).

Devido à improbabilidade de esclarecer a totalidade dos fenômenos, a investigação dos registros das respondentes se revelou por meio do reconhecimento de temas hermenêutico-fenomenológicos, que representaram e delinearam a composição e o âmago do fenômeno investigado (FREIRE, 2012). Ao trabalharmos com temas, assumimos que "os fenômenos da experiência humana são fontes inesgotáveis de investigação, interpretações e reinterpretações" (FREIRE, 2012, p.187):

É importante salientar que a abordagem hermenêuticofenomenológica possibilita que tenhamos um olhar diferenciado em relação aos fenômenos, pois durante o processo de interpretação e de tematização, debruçamo-nos sobre os textos sem buscar por categorias pré-estabelecidas pela literatura da área em relação ao fenômeno sendo investigado ou tentar ajustar os temas que emergem dos textos a categorias já discutidas, ou que são esperadas em trabalhos na área. Desta forma, estamos atentos e abertos ao novo e ao inesperado, contando com um olhar complexo sobre os textos, o que nos permite confirmar aspectos já mencionados pela literatura e por outras pesquisas, mas não nos restringindo a elas, possibilitando revisitações, novas visões e desdobramentos (D'ESPOSITO; COSTA NEVES; 2015, p.250) 
Os temas hermenêutico-fenomenológicos que emergiram por meio dos procedimentos interpretativos realizados foram: ATUAÇÃO, EXPERIÊNCIA DE VIDA, FORMAÇÃO, APOIO, SER PROFESSOR, ESPAÇO ESCOLAR.

Para as três respondentes presentes trabalhar a questão ambiental é importante por meio de ações de EA crítica. Sobre a ATUAÇÃO, a primeira respondente relatou já terem desenvolvido na unidade escolar um projeto de coleta seletiva e descarte do lixo:

Nos dias de hoje, dificilmente deixamos de encontrar em escolas alguma atividade que não seja reconhecida pela comunidade escolar como sendo uma atividade que denominem de Educação Ambiental. As famosas atividades com lixo, coleta seletiva, reutilização de materiais descartados, entre outras. [...] No entanto, em minha avaliação, a realidade socioambiental, mesmo no entorno dessas escolas, tem sofrido transformações pouco significativas e os problemas ambientais só têm se agravado (GUIMARÃES, 2011, p.22-23).

Não desconsiderando a importância de atividades como as supracitadas anteriormente, as ações de EA dentro da perspectiva crítica precisam transpor o reducionismo e superficialidade de trabalhos pontuais, devendo proporcionar a comunidade escolar a possibilidade de adquirir conhecimentos, valores e atitudes necessárias para proteger e melhorar o Meio Ambiente em que vivem.

Mesmo diante das limitações, elas tentam aproximar o ensino à realidade deles, desenvolvendo atividades como passeios e palestras. Realizam ações de problematização e trabalhos em datas comemorativas que estimulam o respeito mútuo dos discentes. Nas práticas cotidianas tentam articular a questão local com a global, por meio da vivência escolar com o que aprendem na escola. Utilizam vídeos informativos para comparar a realidade histórica com que a eles vivenciam. Propõem rodas de conversa para que eles possam discutir e fornecer a contribuição deles.

Nesse tocante, a interpretação do tema EXPERIÊNCIA DE VIDA evidencia que as docentes tentam aproximar ao máximo os conhecimentos disciplinares dos provenientes da experiência de vida dos educandos. O saber ambiental representa um importante articulador:

O saber ambiental não se esgota na finalização (aplicação) do conhecimento existente para resolver problemas complexos [...] Emerge da falta insaciável de conhecimento que impede o saber para a busca de novos sentidos de civilização, novas compreensões teóricas e novas formas práticas de apropriação do mundo (LEFF, 2011, p. 149). 
Nesse sentido, os saberes integram princípios e valores ecologistas; sabedorias tradicionais de manejo; ciência e técnicas que servem de suporte ao desenvolvimento sustentável (LEFF, 2006). Considerar esses saberes pode colaborar para a formação abrangente uma vez que suscita a integralidade do conhecimento pautado na interdisciplinaridade, ao promover a articulação dos conteúdos disciplinares e contextos locais a serem trabalhados.

A interpretação dessa assertiva já nos leva ao tema da FORMAÇÃO. Todas as respondentes acreditam que a EA colabora com a formação do aluno, indo além de abordagens a temas relacionados à Ecologia, envolvendo toda a comunidade escolar. A desestruturação familiar é alta, e a falta de apoio e estímulos dos pais e/ou responsáveis influencia diretamente no interesse dos alunos para tal. Isso justificaria os altos índices de evasão escolar.

O tema APOIO denota um descomprometimento, sejam dos familiares ou de órgãos responsáveis, com o reconhecimento do significativo papel escolar para promover a humanização e emancipação do indivíduo. Elas relataram não haver parcerias com a outra unidade escolar do povoado, acreditando ser um desperdício não trabalharem juntas, devido à grande riqueza ambiental do povoado. As ações até começam na escola, mas não progridem, instaurando um sentimento de ficarem de "mãos atadas", pois sozinhas não conseguem nada. A falta da coletividade aparece como um complicador, pois:

[...] a constituição de um ambiente educativo nesta perspectiva deve promover a passagem do comportamento individual inconsciente (preso à armadilha paradigmática), para práticas coletivas conscientes. Isto como forma de possibilitar que práticas ingênuas individualizadas, que reforçam o espontaneísmo e um ativismo dicotomizado da reflexão presentes na visão educativa tradicional hegemônica e que conforma uma Educação Ambiental conservadora, sejam superadas por práticas refletidas, com a intencionalidade de fazer diferente, que se realizam na interação de indivíduos inseridos na coletividade (GUIMARÃES, 2014, p.8).

Mesmo as respondentes possuindo reflexões críticas do processo educativo, as ações acabam sendo pontuais, não tocando na raiz do problema. Ainda que detenham anseios por modificações em suas práticas pedagógicas, e saibam como fazê-las, muitas vezes estão presas a padrões estruturais dominantes que impedem essa superação e acabam caindo na armadilha paradigmática, que ocorre quando:

[...] o educador por estar atrelado a uma visão (paradigmática) fragmentária, simplista e reduzida da realidade, manifesta (inconscientemente) uma compreensão limitada da problemática ambiental e que se expressa por uma 
incapacidade discursiva que informa uma prática pedagógica fragilizada de Educação Ambiental (GUIMARÃES, 2014, p.4).

Mesmo diante dessas "amarras invisíveis", no tema SER PROFESSOR, as docentes expressaram ver na profissão docente a oportunidade de contribuírem com a comunidade em que cresceram. Comumente, comunidades advindas de povoado são taxadas de incapazes, pelos baixos índices de aprovação no vestibular. Para elas, os professores têm responsabilidades em auxiliar seus alunos a refletirem sobre o futuro.

Segundo Silva e Araújo (2019, p.85) "o educador ambiental pode criar possibilidades de reflexão acerca da sua realidade local/global, considerando os contextos e as subjetividades dos sujeitos envolvidos, com vistas à construção de um conhecimento inter/transdisciplinar". Por consequência, o reconhecimento acerca da complexidade da realidade em que estão imergidos, pode levar à cognição dos docentes sobre a imprescindibilidade de subsumir proposituras de ações e intervenções sócio-políticas no processo educativo, em prol do bem coletivo.

Nessa perspectiva, o tema ESPAÇO ESCOLAR foi explicitado como um lugar de formação e construção de conhecimento de um saber, de ensino e de transformação. Um espaço de avançar na família, na comunidade e na sociedade, sendo o local dos sonhos e realizações. Logo, quem não frequenta a escola, não os realiza. Entretanto, para elas, diante da diversidade e complexidade de problemas existentes, também é o lugar da problemática, pois encontram na escola todo o tipo de problema, tais como desestruturação familiar, pobreza, fome, desnutrição, abandono, etc. "A escola tem sido historicamente o espaço indicado para a discussão e o aprendizado de vários temas urgentes e de atualidade, como o resultado da sua importância na formação do cidadão" (REIGOTA, 1998, p.47).

O educador ambiental assumiria assim, a responsabilidade de coordenar atividades, estimular a percepção, a criatividade, o discernimento crítico sobre os problemas ambientais e sugestões para resolvê-los:

Trata-se de fomentar-lhes capacidades, de modo que desenvolvam o conhecimento pessoal com relação ao meio em que vivem, sustentados por um pensamento crítico. A aprendizagem deveria ser, deste modo, um processo de produção de significações e de apropriação subjetivado conhecimento (RODRIGUES; SILVA, 2010, p.141).

Ao participar do processo de construção ativa do conhecimento, a comunidade escolar abandonaria a passividade. Sendo assim, assumiria, por conseguinte, a atividade e reflexividade sobre os principais problemas 
socioambientais locais e o desenvolvimento de pensamentos integrados, a fim de alcançarem soluções comuns.

Dentre os problemas relatados, foi bastante evidenciado a carência de assistência e de orientação para que possam melhorar suas atividades relacionadas à $E A$, além de lidarem melhor com as diversas problemáticas existentes, a fim de superá-las:

[...] pensar a formação do professor para a Educação Ambiental supera a acepção do profissional preparado para resolver problemas de ensino/aprendizagem diante recursos instrumentais e selecionar meios técnicos mais apropriados para propósitos específicos. Esta perspectiva, posta nos cursos de formação, não dá conta de responder questões que se apresentam em muitas situações concretas no cotidiano escolar e aos objetivos propostos pela educação para as transformações sociais (ARAÚJO, 2004, p.77).

De acordo com a Lei $n^{\circ} .9394$, todos os professores precisam buscar a sua formação, visando avanços na metodologia educacional. Para tanto, é competência de todos os órgãos municipais promoverem estratégias para essa formação e capacitação em serviço, propiciando a associação entre teoria e pratica (ARANTES; MONKEN, 2014). Neste sentido, anualmente a Secretaria de Educação Municipal (SEMED) de Itaporanga/SE oferece uma formação para as profissionais da rede, com temáticas pré-estabelecidas.

Apesar de reconhecerem a importância dos esforços da SEMED, o processo não subsidia a preparação tangente a cada realidade das escolas do município, pois não refletem as insuficiências peculiares da região. À vista disso, partindo das idiossincrasias percebidas na conversa, surge a propositura de uma formação docente contra hegemônica que atenda às necessidades colocadas pelas respondentes, e orienta à implementação da Comissão de Meio Ambiente e Qualidade de Vida (COM-VIDA) na unidade escolar.

\section{Subversividade e resistência: emergindo a propositura de uma formação docente sob a perspectiva Educação Ambiental crítica}

Partindo da reflexão acerca dos relatos, elaboramos uma proposta objetivando promover uma formação docente continuada (Quadro 1) para que a comunidade escolar possa desenvolver projetos socioambientais em longo prazo, contando com parcerias de órgãos competentes. 
Quadro 1: O quadro ilustra a proposta de formação docente elaborada.

\begin{tabular}{|c|c|c|c|c|}
\hline \multicolumn{5}{|c|}{$\begin{array}{l}\text { PREFEITURA MUNICIPAL DE ITAPORANGAD'ÁJUDA } \\
\text { SECRETARIA MUNICIPAL DE EDUCAÇÃO } \\
\text { ESCOLA MUNICIPAL JOSÉ SOBRAL GARCEZ FILHO } \\
\text { ITAPORANGA- SE }\end{array}$} \\
\hline \multicolumn{5}{|c|}{ PROPOSTA DE FORMAÇÃO DE PROFESSORES EM EA CRÍTICA } \\
\hline \multicolumn{5}{|c|}{ IDENTIFICACCÃO } \\
\hline Unidade Escolar & \multicolumn{4}{|c|}{ ESCOLA MUNICIPAL JOSÉ SOBRAL GARCEZ FILHO } \\
\hline $\begin{array}{l}\text { Equipe } \\
\text { Responsável }\end{array}$ & \multicolumn{4}{|c|}{ Integrantes do Projeto Sala Verde } \\
\hline Público-alvo & \multicolumn{2}{|c|}{ Docentes e Funcionários da Unidade } & Carga Horária Total & 160 horas \\
\hline Período & \multicolumn{4}{|c|}{\begin{tabular}{|l|l} 
Ano letivo de 2020 & Carga Horária Semanal \\
\end{tabular}} \\
\hline \multirow{2}{*}{\multicolumn{5}{|c|}{$\begin{array}{c}\text { Formação Docente em Educação Ambiental Crítica } \\
\text { OBJETIVOS DE APRENDIZAGEM }\end{array}$}} \\
\hline & & & & \\
\hline \multicolumn{5}{|c|}{$\begin{array}{l}\text { Promover uma formação continuada para que os docentes possam desenvolver projetos que trabalhem a } \\
\text { longo prazo com problemas socioambientais com o envolvimento de todos da comunidade e órgãos } \\
\text { competentes. }\end{array}$} \\
\hline \multicolumn{5}{|c|}{ CONTEÚDO PROGRAMÁTICO } \\
\hline \multicolumn{2}{|c|}{$\begin{array}{l}\text { - Educação Ambiental Crítica; } \\
\text { - Saber ambiental; } \\
\text { - A função social da EA: participação e engajamento } \\
\text { dos educandos; }\end{array}$} & $\begin{array}{l}- \text { Met } \\
\text { - Forr } \\
\text { - Con } \\
\text { (CON }\end{array}$ & $\begin{array}{l}\text { gias ativas; } \\
\text { o do educador ambiental; } \\
\text { AS). }\end{array}$ & de Vida \\
\hline \multicolumn{5}{|c|}{ METODOLOGIA } \\
\hline \multicolumn{5}{|c|}{$\begin{array}{l}\text { Adotaremos uma adaptação da Metodologia da Problematização (MP), que é pautada no Método do Arco, } \\
\text { consistindo em } 5 \text { etapas que subsidiarão os módulos da formação: } 1^{\text {a }} \text { Observação da realidade (social e } \\
\text { concreta); } 2^{\text {a }} \text { Pontos-chave; } 3^{\text {a }} \text { Teorização; } 4^{\underline{a}} \text { Hipóteses de Solução; } 5^{\text {a }} \text { Aplicação á Realidade (prática). }\end{array}$} \\
\hline \multicolumn{5}{|c|}{ MÓDULOS } \\
\hline \multicolumn{5}{|c|}{$\begin{array}{c}\text { Cada uma das etapas acima relatadas serão abordadas em cada módulo } \\
\text { MÓDULO I - } 20 \text { HORAS }\end{array}$} \\
\hline ETAPA & \multicolumn{4}{|c|}{ Diagnóstico de necessidades dos professores } \\
\hline OBJETIVO & \multicolumn{4}{|c|}{$\begin{array}{l}\text { Efetuar um levantamento dos pontos principais a serem problematizados na formação } \\
\text { partir das falas dos docentes, com relação aos problemas socioambientais que } \\
\text { acometem a comunidade da Caueira/SE. }\end{array}$} \\
\hline EXECUÇÃO & \multicolumn{4}{|c|}{$\begin{array}{l}\text { Aplicação da metodologia "OFICINA DO FUTURO", pautada nas seguintes etapas: } 1 \text {. } \\
\text { Árvore dos sonhos: onde os docentes falaram de seus desejos e anseios; } 2 \text {. Pedras } \\
\text { no Caminho: para que eles pensem nos obstáculos existentes que dificultam a } \\
\text { realização do que desejam; } 3 \text {. Jornal Mural: reunião de informações, para conhecer a } \\
\text { história escola e da comunidade, para compreender a razão das dificuldades existirem; } \\
\text { 4.Plano de ação: irão pensar sobre a necessidade de planejar ações que se articulem } \\
\text { ao PPP que está em construção. }\end{array}$} \\
\hline $\begin{array}{l}\text { REFERÊNCIAS } \\
\text { SUGERIDAS }\end{array}$ & \multicolumn{4}{|c|}{$\begin{array}{l}\text { ARAÚJO, J. B. S.,SILVA, C. J. da, SANTANA, C. G. Oficina do Futuro como } \\
\text { Metodologia de Formação Inicial com Alunos do PIBID. Disponível em } \\
\text { https://eventos.set.edu.br/index.phpqenfope/article/viewFile } \\
\text { BRASIL. Ministério da Educação. Secretaria de Educação Continuada, Alfabetização, } \\
\text { Diversidade e Inclusão.Formando Com-vida, Comissão de Meio Ambiente e Qualidade } \\
\text { de Vida na Escola : construindo Agenda } 21 \text { na escola / Ministério da Educação, } \\
\text { Ministério do Meio Ambiente.- 3. ed., rev. e ampl. - Brasília : MEC, Coordenação-Geral } \\
\text { de Educação Ambiental, 2012. }\end{array}$} \\
\hline
\end{tabular}

Continua... 


\begin{tabular}{|c|c|}
\hline \multicolumn{2}{|r|}{ MÓDULO II - 20 HORAS } \\
\hline ETAPA & Seleção dos pontos-chave \\
\hline OBJETIVO & $\begin{array}{l}\text { Selecionar as principais temáticas a serem conceituadas e aprendidas, a fim de } \\
\text { promover um melhor entendimento das problemáticas a serem trabalhadas }\end{array}$ \\
\hline EXECUÇÃO & $\begin{array}{l}\text { A partir da oficina do futuro, os docentes irão identificar quais são os pontos-chave a } \\
\text { serem problematizados }\end{array}$ \\
\hline $\begin{array}{l}\text { REFERÊNCIAS } \\
\text { SUGERIDAS }\end{array}$ & $\begin{array}{l}\text { BERBEL, N. A. N. BERBEL, Neusi Aparecida Navas. A problematização e a } \\
\text { aprendizagem baseada em problemas: diferentes termos ou diferentes caminhos?. } \\
\text { Interface (Botucatu), Botucatu, v. 2, n. 2, p. 139-154, Feb. } 1998\end{array}$ \\
\hline \multicolumn{2}{|r|}{ MÓDULO III - 40 HORAS } \\
\hline ETAPA & Teorização e reflexão \\
\hline OBJETIVO & $\begin{array}{l}\text { Trabalhar com teóricos que subsidiem as temáticas e embarguem a compreensão } \\
\text { dos conceitos de PARTICIPAÇÃO e SABERES AMBIENTAIS. }\end{array}$ \\
\hline EXECUÇÃO & $\begin{array}{l}\text { Essa participação iniciará com uma palestra instrutiva com especialistas em E.A, } \\
\text { bem como uma fala de um integrante da comunidade no favorecimento dos diálogos } \\
\text { que perpassam essa formação. }\end{array}$ \\
\hline $\begin{array}{l}\text { REFERÊNCIAS } \\
\text { SUGERIDAS }\end{array}$ & $\begin{array}{l}\text { JACOBI, Pedro Roberto; TRISTAO, Martha; FRANCO, Maria Isabel Gonçalves } \\
\text { Correa. A função social da Educação Ambiental nas práticas colaborativas: } \\
\text { participação e engajamento. Cad. CEDES, Campinas, v. 29, n. 77, p. 63-79, Apr. } \\
\text { 2009. } \\
\text { from<hailable } \\
\text { 005\&lng=en\&nrm=iso>. access on } 13 \text { Jan. 2020. http://dx.doi.org/10.1590/S0101- } \\
\text { 32622009000100005 } \\
\text { LEFF, E. Saber Ambiental: sustentabilidade, racionalidade, complexidade e poder. } \\
\text { Petrópolis, Vozes, } 343 \text { p., } 2001 .\end{array}$ \\
\hline \multicolumn{2}{|r|}{ MÓDULO IV - 20 HORAS } \\
\hline ETAPA & Metodologias \\
\hline OBJETIVO & $\begin{array}{l}\text { Propor metodologias pertinentes que auxiliem na elaboração das hipóteses de } \\
\text { soluções para às problemáticas. Assim, será fomentado a construção coletiva do } \\
\text { plano de ação pensado no primeiro módulo }\end{array}$ \\
\hline EXECUÇÃO & $\begin{array}{l}\text { Apresentação da Pedagogia de Projetos (PP), que é inspirada em concepções das } \\
\text { Pedagogias ativas. Sendo assim, a PP é uma metodologia que pode suscitar a } \\
\text { construção do conhecimento integral e significativo, promovendo assim um processo } \\
\text { educacional mais integrativo e interativo }\end{array}$ \\
\hline $\begin{array}{l}\text { REFERÊNCIAS } \\
\text { SUGERIDAS }\end{array}$ & 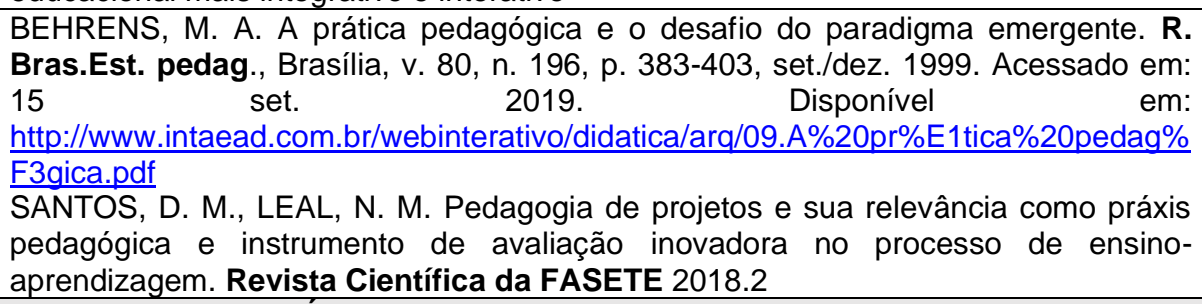 \\
\hline \multicolumn{2}{|r|}{ MÓDULO V - 60 HORAS } \\
\hline ETAPA & Aplicação à realidade do plano de ação \\
\hline OBJETIVO & $\begin{array}{l}\text { Aplicação do plano de ação constituído coletivamente para a formação da Comissão } \\
\text { de Meio Ambiente e Qualidade de Vida (COM-VIDAS) }\end{array}$ \\
\hline EXECUÇÃO & $\begin{array}{l}\text { Para a execução de um plano de ação de forma eficiente e integrativa, alguns } \\
\text { questionamentos devem ser considerados: - Para quem? (quais serão os agentes } \\
\text { envolvidos); - Quando? (período de duração); - Onde? (local em que a ação vai } \\
\text { ocorrer); - Como? (descrição da atividade realizada); - Por quê? (justificativas); - } \\
\text { Para quê? (resultados esperados). } \\
\text { A implementação da COM-VIDA oportuniza a evidenciação de temas ligados à } \\
\text { melhoria da qualidade de vida, conferindo ao espaço escolar a sustentabilidade } \\
\text { necessária para manter o Meio Ambiente conservado e recuperado. Assim, as } \\
\text { relações sociais estabelecidas entre a escola e a comunidade são ressignificadas. }\end{array}$ \\
\hline
\end{tabular}


...continuação.

\begin{tabular}{|c|c|}
\hline \multicolumn{2}{|r|}{ MÓDULO V - 00 HORAS } \\
\hline 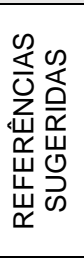 & $\begin{array}{l}\text { BRASIL. Ministério da Educação. Secretaria de Educação Continuada, Alfabetização, Diversidade } \\
\text { e Inclusão.Formando Com-vida, Comissão de Meio Ambiente e Qualidade de Vida na Escola : } \\
\text { construindo Agenda } 21 \text { na escola / Ministério da Educação, Ministério do Meio Ambiente.- 3. ed., } \\
\text { rev. e ampl. - Brasília : MEC, Coordenação-Geral de Educação Ambiental, } 2012 \text {. } \\
\text { GUIMARÁES, M. PROCESSOS FORMATIVOS DO EDUCADOR AMBIENTAL: A PRÁXIS DE } \\
\text { INTERVENCCÂO NUMA (COM)VIVÊNCIA PEDAGÓGICA. Didática e Prática de Ensino na relação } \\
\text { com a Formação de Professores. EdUECE- Livro 2, 2014. }\end{array}$ \\
\hline \multicolumn{2}{|r|}{ RECURSOS DIDÁTICOS } \\
\hline \multirow{2}{*}{\multicolumn{2}{|c|}{$\begin{array}{l}\text { - Notebook e data-show; } \\
\text { - Celular (aplicativo educacional: Bitmoji, Plickers, Gocongr, Salve o Mundo, Vivavídeo). } \\
\text { AVALIAÇÃO FORMATIVA }\end{array}$}} \\
\hline & \\
\hline \multicolumn{2}{|c|}{$\begin{array}{l}\text { - Presença, participação e discussão em sala de aula; } \\
\text { - Elaboração e aplicação do plano de ação; } \\
\text { - Divulgações no Facebook e Instagram Oficiais do projeto dos resultados obtidos. }\end{array}$} \\
\hline
\end{tabular}

Fonte: Autoria própria.

A propositura é embasada na Metodologia da Problematização (MP), pois é indicada no processo de ensino-aprendizagem que requer uma maior criticidade do educando, sendo uma "proposta de ensino, de estudo e de trabalho oportuna em situações em que os temas estejam relacionados com a vida em sociedade" (BERBEL, 1998, p.142).

O momento inicial consistiria em levantar os pontos principais a serem problematizados na formação partir das falas dos docentes com relação aos problemas socioambientais aos quais acometem a comunidade da Caueira (SE). Para tanto, realizaríamos a Oficina do Futuro que "consiste em uma série de passos ou etapas para a construção de projetos coletivos, com duração que pode variar de acordo com o ritmo e o aprofundamento que o grupo deseje" (BRASIL, 2012).

O segundo momento seria a teorização e reflexão, a partir de textos e autores que subsidiem a temática e embarguem a compreensão dos conceitos sobre PARTICIPAÇÃO (comunidade, família, órgãos competentes do Meio Ambiente) e SABERES AMBIENTAIS (conhecimento disciplinar e conhecimento local), elencados como os principais para a superação das problemáticas relatadas.

Prosseguiríamos com o terceiro momento a partir da apresentação de metodologias que eles pudessem utilizar para o desenvolvimento de seus projetos, merecendo destaque a Pedagogia de Projetos (PP). De acordo com Santos e Leal (2018), a PP é inspirada em concepções das Pedagogias ativas, a metodologia pode suscitar a construção do conhecimento integral e significativo, promovendo assim um processo educacional mais integrativo e interativo.

A ressignificação da formação ambiental perpassa pelo estabelecimento de novos caminhos metodológicos, novas formas de ver e interpretar a complexa realidade socioambiental. Nesse contexto, 0 incentivo ao desenvolvimento das práticas interdisciplinares se presenta como uma das possibilidades de novas abordagens formativas (SILVA; ARAÚJO, 2019, p.87) 
O uso da PP no trabalho docente pode auxiliar na formação integral do discente ao oportunizar uma aprendizagem conceitual, atitudinal, procedimental. Além disso, suscita a integralidade do conhecimento pautado na interdisciplinaridade, pois promove a articulação disciplinar dos conteúdos e contextos a serem trabalhados (SANTOS; LEAL, 2018).

Para evitar essa desarticulação e a reprodução do que é criticado, a etapa de construção/reconstrução do plano de ação integrativo e sua aplicação são imprescindíveis. Para tanto, alguns questionamentos devem ser considerados: - Para quem? (quais serão os agentes envolvidos); - Quando? (período de duração); - Onde? (local em que a ação vai ocorrer); - Como? (descrição da atividade realizada); - Por quê? (justificativas); - Para quê? (resultados esperados) (BRASIL, 2012). Tais procedimentos são indispensáveis para a implementação da COM-VIDA.

O principal papel da COM-VIDA é realizar ações voltadas à melhoria do meio ambiente e da qualidade de vida, promovendo o intercâmbio entre a escola e a comunidade, e contribuir assim para um dia a dia participativo, democrático, inclusivo, animado e saudável. (BRASIL, 2012, p.15)

A instituição da comissão pode subsidiar a transformação do espaço escolar, suscitando a reflexão acerca das resoluções dos problemas atuais, rumo a busca de um melhor futuro comum. Além disso, fomentaria a coletividade e o apoio tão carentes nas unidades escolares a fim de minimizar a falta de comunicação entre as mesmas e de unir as forças.

Em vista disso, uma sociedade mais justa e igualitária pode ser fundada por esses renovados profissionais da educação. Essa nova fundação requer a autonomia e a participação discente na construção de seus saberes. Assim, não há logicidade na continuidade de formações que fomentem um processo de ensino-aprendizagem compartimentado, pautado em um currículo fraturado e desconectado das transformações sociais e das vidas dos educandos.

\section{Conclusões}

O presente artigo não pretende ser conclusivo, diante da complexidade das temáticas abordadas, que exigem um esforço multidimensional para o seu aprofundamento e para a construção de novos caminhos ou alternativas. No entanto, as discussões nos levam a inferir que a formação em EA deve fornecer subsídios aos professores, a fim de que possam possibilitar a seus alunos capacidades de analisar, conhecer e compreender, de modo integralizado e sistêmico, as noções básicas relacionadas às problemáticas socioambientais.

Educadores ambientais e comunidade escolar precisam se preocupar 
levem a interações construtivas, justas e ambientalmente sustentáveis. A principal relevância deste trabalho foi mostrar necessidade de repensar e reconstruir os programas de formação docente, evidenciando a pertinência da emergência de um educador ambiental crítico para a comunidade escolar, apontando para a premência da ruptura efetiva com o paradigma educacional dicotômico, que exclui as diferentes formas de saberes, alijando a autonomia discente. A assimilação desses alvitramentos pode contribuir para a reformulação da concepção de escola e da sua função social.

É preciso que a formação dialetize as contradições circunscritas na busca de sociedades sustentáveis, ou seja, é necessário realizar a defesa do que se almeja, combatendo o que é imposto hegemonicamente. Devolver-se-ia assim ao educador os poderes de contestação e subversão, subtraídos historicamente da EA brasileira (LAYRARGUES, 2018).

Partindo da emergência dessa acepção, a formação de profissionais educadores ambientais críticos precisa estimular novos encaminhamentos da prática educativa por meio de atividades reflexivas. Possibilita-se assim, o desenvolvimento de procedimentos e valores básicos para o exercício pleno da cidadania sustentável e consciente dos seus atos.

Portanto, ao refletirmos sobre a EA dentro das unidades escolares é necessário que o processo educativo esteja engendrado pela participação integrada da comunidade escolar. A escola para cumprir sua função transformadora, contribuindo para a democratização da sociedade, precisa garantir que os sujeitos sociais por ela formados, apropriem-se de forma crítica e reflexiva do saber elaborado pela cultura à qual pertencem.

A formação docente para uma EA crítica traz para o ser humano uma nova ética, ao mesmo tempo em que mostra a necessidade de uma conscientização coletiva, pautada num princípio que mostra que todo ser humano possui sua responsabilidade a cumprir para com o Meio Ambiente. A instauração da COM-VIDA oportunizaria a evidenciação de temas ligados à melhoria da qualidade de vida, podendo conferir aos espaços escolares a sustentabilidade necessária para manter o meio ambiente conservado e recuperado. Assim, as relações sociais estabelecidas entre a escola e a comunidade seriam ressignificadas e harmoniosas (BRASIL, 2012).

O educador ambiental pode sensibilizar as pessoas para que elas interiorizem os problemas socioambientais, de modo haver mudanças de comportamento e adotem atitudes para solucioná-los. Essas soluções serão factíveis se houver envolvimento e participação de toda a comunidade escolar, mudança de hábitos dos docentes, juntamente com 0 apoio de políticas públicas condizentes, pois tais problemas não podem ser resolvidos individualmente, nem por movimentos isolados das comunidades (SANTOS, et al., 2013).

Contudo, é preciso esclarecer que a EA não é a solução para todos os problemas ambientais. Percebemos dificuldades em se estabelecer práticas 
adequadas, dialógicas e críticas, devido aos condicionantes estruturais e/ou carências de parcerias. Assim, é preciso ter cuidado com as armadilhas paradigmáticas, pois, indubitavelmente, um dos maiores desafios para os docentes é a transposição prática do que está consolidado pelo paradigma educacional brasileiro atual.

Como a caracterização da prática pedagógica está alicerçada nos paradigmas cuja construção sócia histórica é acompanhada por crenças e valores, é preciso promover reflexões profundas que tragam uma "reparadigmatização" da formação docente em EA crítica, a fim de atender às necessidades e expectativas da sociedade atual. Nesse sentido, são requeridos processos constantes de autorreflexão, subversão e resistência, rumo às mudanças essenciais para a reedificação dos pilares dos programas de formação vigentes.

\section{Agradecimentos}

Às docentes responsáveis pela disciplina Dr. Maria Inêz Oliveira Araújo e Dr. Aline Lima de Oliveira Nepomuceno, pelo trabalho de campo oportunizado; às funcionárias da Escola Municipal José Sobral Garcez Filho, pelo tempo disponibilizado.

\section{Referências}

ARANTES, L. M.; MONKEN, E. M. F. A atuação de educadores ambientais na formação de professores de escolas municipais de Belo Horizonte (MG), no Programa Escola Integrada Inhotim. Acta Biológica Catarinense, jul.-dez.; 1(2): 36-45, 2014.

ARAÚJO, M. I. O. A universidade e a formação de professores para a Educação Ambiental. Revista Brasileira de Educação Ambiental, Brasília, n. 0, p. 71-78, Nov./2004.

BERBEL, N. A. N. A problematização e a aprendizagem baseada em problemas: diferentes termos ou diferentes caminhos? Interface (Botucatu), Botucatu, v. 2, n. 2, p. 139-154, Feb. 1998.

BRASIL. Ministério da Educação. Secretaria de Educação Continuada, Alfabetização, Diversidade e Inclusão. Formando COM-VIDA, Comissão de Meio Ambiente e Qualidade de Vida na Escola: construindo Agenda 21 na escola / Ministério da Educação, Ministério do Meio Ambiente. 3. ed. rev. e ampl. - Brasília: MEC, Coordenação-Geral de Educação Ambiental, 2012.

D'ESPOSITO, M. E. W.; COSTA NEVES, R. da. Pesquisando a partir da perspectiva da complexidade na área de linguística Aplicada. DELTA, São Paulo, v. 31, n. 1, p. 239-259, June 2015.

DIAS, G.F. Educação Ambiental: princípios e práticas. São Paulo: Gaia, 2004. 
FREIRE, M. M. Da aparência à essência: a abordagem hermenêuticofenomenológica como orientação qualitativa de pesquisa. In: ROJAS, J.; MELLO, L.S. (Org.). Educação, pesquisa e prática docente em diferentes contextos. 1ed. Life Editora, v. 1, 2012, p. 181-199.

GUIMARÃES, M. Armadilha paradigmática na Educação Ambiental. In: LOREIRO, C. F. B., LAYRARGUES, P. P., CASTRO, R. S. (orgs.). Pensamento complexo, dialética e Educação Ambiental. $2^{\mathrm{a}}$ ed. São Paulo: Cortez, 2011.

GUIMARÃES, M. Processos formativos do educador ambiental: a práxis de intervenção numa (com)vivência pedagógica. Didática e Prática de Ensino na relação com a Formação de Professores. EdUECE, 2014, Livro 2 - 05829.

JACOBI, P. R.; TRISTAO, M.; FRANCO, M. I. G. C. A função social da Educação Ambiental nas práticas colaborativas: participação e engajamento. Cad. CEDES, Campinas, v. 29, n. 77, p. 63-79, Apr. 2009.

LAYRARGUES, P. P. Subserviência ao capital: Educação Ambiental sob o signo do antiecologismo. Pesquisa em Educação Ambiental, vol.13, n.1 pags. 28-47, 2018.

LEFF, E. Saber Ambiental: sustentabilidade, racionalidade, complexidade, poder. $4^{\circ}$ ed. Petrópolis, RJ: Vozes, 2011.

LEFF, E. Racionalidade Ambiental: a reapropriação social da natureza. Rio de Janeiro: Civilização Brasileira, 2006.

SANTOS, D. M., LEAL, N. M. Pedagogia de projetos e sua relevância como práxis pedagógica e instrumento de avaliação inovadora no processo de ensino-aprendizagem. Revista Científica da FASETE. 2018.2.

SANTOS, R. M. de S. dos et al. A necessidade de uma nova conscientização ambiental: A Educação Ambiental como prática. Revista brasileira de Educação e saúde (Pombal - PB, Brasil), v. 3, n. 2, p. 28-33 abr.-jun., 2013.

SILVA, J.S, ARAÚJO, M.I.O. O estágio de docência e a formação de professores em Educação Ambiental: reflexões e práticas. In: NEPOMUCENO, A.L.O., ARAÚJO, M.I.O. (orgs). Docência: caminhos por diferentes referências [recurso eletrônico] - São Cristóvão, SE: Editora UFS, p. 79-100, 2019.

REIGOTA, M. Desafios à Educação Ambiental escolar. In: JACOBI, P. et al. (orgs.). Educação, meio ambiente e cidadania: reflexões e experiências. São Paulo: SMA, 1998. p.43-50.

REIGOTA, M. Meio ambiente e representação social. São Paulo: Cortez, 2007.

RODRIGUES, J. M. M., SILVA, E. V. da Silva. Educação Ambiental e Desenvolvimento Sustentável: Problemática, Tendências e Desafios. $2^{2}{ }^{a}$ ed. Fortaleza: Edições UFC, 2010. 